\title{
Monitoring of exposure to methylpentanes by diffusive sampling and urine analysis for alcoholic metabolites
}

Toshio Kawai, Kazunori Mizunuma, Tomojiro Yasugi, Shun'ichi Horiguchi, Hiroshi Iguchi, Antonio Mutti, Sergio Ghittori, Masayuki Ikeda

\begin{abstract}
Objectives-To investigate the possibilities of personal ambient monitoring and biological monitoring for methylpentane isomers.

Methods-The performance of activated carbon cloth to absorb 2- and 3-methylpentane was studied by experimental vapour exposure followed by solvent extraction and gas chromatography (GC). Urine from workers and rats exposed to 2- and 3-methylpentane was analysed by GC with or without acid or enzymatic hydrolysis.
\end{abstract}

Results-Carbon cloth absorbed 2- and 3-methylpentane linearly to exposures up to eight hours and to $400 \mathrm{ppm}$, and was sensitive enough to detect a 15 minute peak of exposure. The two isomers were clearly separated from hexane on a DB-1 column. For analysis of the urine, enzymatic hydrolysis was superior to acid hydrolysis. Exposure of rats to methylpentane vapours showed that 2-methyl-2-pentanol and 3-methyl2-pentanol were excreted in urine in proportion to the dose of 2-methylpentane and 3-methylpentane, respectively. 2Methyl derivatives of 1-, 3-, and 4propanol, 2-methylpentane-2,4-diol, and 3-methyl-2-pentanol were minor metabolites. Analysis of urine from the exposed workers showed that 2-methyland 3-methyl-2-pentanol are leading urinary metabolites after exposure to the corresponding methylpentane.

Conclusions-Diffusive sampling is applicable to monitor 2- and 3methylpentane vapours as is the case for hexane vapour. 2-Methyl-2-pentanol and 3-methyl-2-pentanol will be markers of occupational exposure to 2-methylpentane and 3-methylpentane, respectively. Also, 2-methylpentane-2,4-diol might be a marker of exposure to 2methylpentane

(Occup Environ Med 1995;52:757-763)

Keywords: biological monitoring; urine analysis; methylpentanes; diffusive sampling

Two methylpentane isomers, 2-methylpentane and 3-methylpentane, are present in glue thinner, as impurities in some commercial hexane preparations, ${ }^{1-3}$ and as important components in solvent mixtures. ${ }^{45}$ According to Ono et al, they are less toxic to the peripheral nervous system than hexane. ${ }^{1}$ It is quite conceivable that the metabolism of these isomers leading to corresponding alcohols ${ }^{6}$ should be different from that of hexane (for which 2,5-hexanedione in urine is a biological marker of exposure $^{78}$ ). Only a few studies ${ }^{29}$ have been conducted to investigate the possibilities of the use of these alcoholic metabolites in urine in biological monitoring of workers occupationally exposed to the methylpentane isomers.

Trials were made in this study to examine if the following two approaches are applicable to exposure monitoring: (a) diffusive samplers equipped with carbon cloth, which is effective for the measurement of time weighted average vapour concentrations of various solvents including hexane ${ }^{7}$ and $(b)$ analysis of the urine for alcoholic metabolites with or without pretreatment by acid or enzymatic hydrolysis. ${ }^{7}$

\section{Materials and methods}

URINE SAMPLES

Two types of urine samples were examined. Human urine samples were collected from three male workers from a shoe making factory in Italy, who were exposed to the vapours of solvent mixture preparations containing methylpentane isomers. Fifteen non-exposed male subjects served as controls. Also, urine samples were collected from female Wistar rats (four animals (that weighed about 200 g)/dose) exposed to $50,100,200$, or $400 \mathrm{ppm}$ of 2- or 3-methylpentane for eight hours in a dynamic exposure chamber system ${ }^{10}$; collection was performed 24 hours after initiation of the exposures.

\section{EXPOSURE OF DIFFUSIVE SAMPLERS TO 2- OR 3-METHYLPENTANE}

Diffusive samplers ${ }^{11-13}$ equipped with carbon cloth KF-1500 (Toyobo, Osaka, Japan) were exposed to 2- or 3-methylpentane vapours in parallel to the exposure of rats.

\section{GAS CHROMATOGRAPHIC ANALYSIS}

A gas chromatograph (GC) equipped with a flame ionisation detector (Model 5890, Hewlett-Packard) connected to an automatic liquid sampler (Model 7673A, HewlettPackard) was used throughout the study. Solvents adsorbed on the carbon cloth were extracted with $5 \mathrm{ml}$ carbon disulphide (spiked with $0 \cdot 2 \mu \mathrm{g} / \mathrm{ml}$ of $t$-butylbenzene) as previously described. ${ }^{7}$ An aliquot of the extract, $1 \mu \mathrm{l}$ injection, was introduced to the GC and 


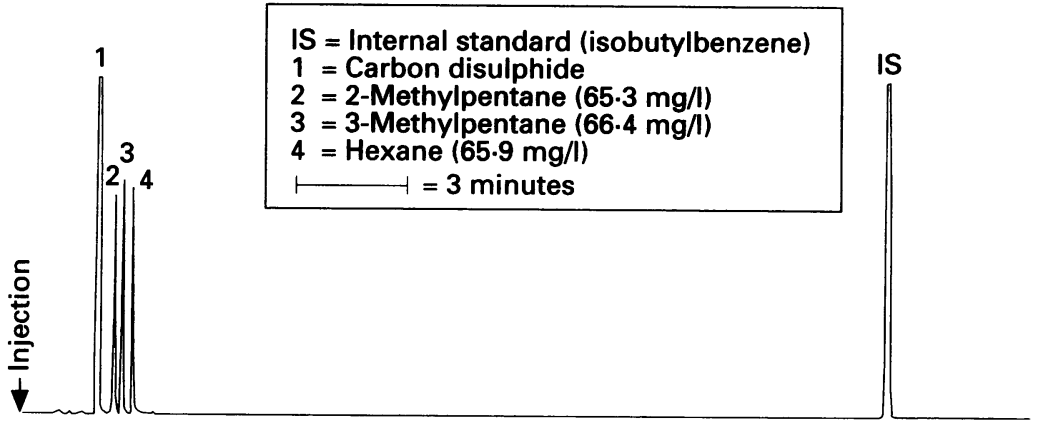

Figure 1 A chart to show separation of 2-methylpentane and 3-methylpentane from hexane on the chromatogram. For analytical conditions, see the materials and methods section. Isobutylbenzene is used as an internal standard (IS). Peaks are: 1, carbon disulphide; 2, 2-methylpentane (65.3 mg/l); 3, 3-methylpentane $(66.4 \mathrm{mg} / \mathrm{l}) ; 4$, hexane (65.9 mg/l). non-exposed workers were fortified with the metabolites. The detection limits for monoalcohols in urine after dichloromethane extraction (by the direct method) were about 0.05 $\mathrm{mg} / \mathrm{l}$ of urine, but that for 2-methylpentane2,4-diol was $0.1 \mathrm{mg} / 1$ of urine possibly reflecting its poor extraction efficiency (table 1). The overall reproducibility when analysed by the direct method was considered to be satisfactory because the coefficients of variation after three measurements were less than $3 \%$ for all the metabolites.

\section{GAS CHROMATOGRAPHY-MASS SPECTROMETRY} (GC-MS)

Analysis by GC-MS was conducted as previously described, and identification of chemicals were made with reference to the National Bureau of Standards mass library. ${ }^{14}$

analysed on a DB-1 mega-bore column (30 $\mathrm{mm}$ in length, $0.53 \mathrm{~mm}$ in inner diameter and $1.5 \mu \mathrm{m}$ in film thickness). The column was kept at $40^{\circ} \mathrm{C}$ for seven minutes and then heated at a rate of $5^{\circ} \mathrm{C} / \mathrm{min}$ to reach $120^{\circ} \mathrm{C}$ at which temperature it was kept until the end of the analysis. Both the injection port and the detectors were kept at $250^{\circ} \mathrm{C}$. Figure 1 shows clear separation of the two methylpentanes from hexane on the column. The method was highly reproducible with coefficients of variation of less than $3 \%$ when $2-$ and 3-methylpentane were determined five times each.

For urine analysis, three types of pretreatment were examined, the direct method (or the analysis without hydrolytic pretreatment), the acid hydrolysis method, and the enzymatic hydrolysis method. ${ }^{7}$ In practice, $5 \mathrm{ml}$ of each urine sample was mixed with either $0.25 \mathrm{ml}$ of $35 \%$ hydrochloric acid (the acid hydrolysis method) or $0.5 \mathrm{ml}$ of a $\beta$-glucuronidasesulphatase preparation (for the source, see the reagent section to follow; the enzymatic hydrolysis method) and kept at $100^{\circ} \mathrm{C}$ for 30 minutes or at $36^{\circ} \mathrm{C}$ for 24 hours, respectively. Either the hydrolysed urine or $5 \mathrm{ml}$ of the unhydrolysed urine (the direct method) was extracted with $2 \mathrm{ml}$ of dichloromethane (spiked with $9.2 \mathrm{mg}$ of 3-methyl-cyclohexanone/ml dichloromethane). The extract, $2 \mu \mathrm{l} /$ injection, was analysed on the DB-1 megabore column already described. The column was kept at $40^{\circ} \mathrm{C}$ for seven minutes and then heated at a rate of $5^{\circ} \mathrm{C} / \mathrm{min}$ to reach $120^{\circ} \mathrm{C}$ at which temperature it was kept till the end of analysis. Both the injection port and the detectors were kept at $250^{\circ} \mathrm{C}$. The peak areas were proportional to concentration up to the highest concentrations of all metabolites studied (15 mg each/1 urine) when urine samples from

Table 1 Extraction efficiencies for possible metabolites

\begin{tabular}{ll}
\hline Metabolites & Extraction efficiency (\%) \\
\hline 2-Methyl-1-pentanol & $88 \cdot 3$ \\
2-Methyl-2-pentanol & $79 \cdot 1$ \\
2-Methyl-3-pentanol & $84 \cdot 5$ \\
2-Methyl-4-pentanol & $82 \cdot 7$ \\
2-Methyl-3-pentanone & $74 \cdot 3$ \\
2-Methylpentane-2,4-diol & $8 \cdot 7$ \\
3-Methyl-2-pentanol & $82 \cdot 9$ \\
2-Methyl-3-pentanol & $77 \cdot 3$ \\
2-Methyl-2-pentanone & $89 \cdot 0$ \\
\hline
\end{tabular}

\section{REAGENTS}

The following authentic chemicals were purchased from Nacalai Tesque (Kyoto, Japan); 2-methylpentane, 2-methyl-1-pentanol, 2methyl-2-pentanol, 2-methyl-3-pentanone, 2methyl-3-pentanol, 2-methyl-4-pentanol, 2-methylpentane-2,4-diol, 3-methylpentane, 3-methyl-2-pentanone, 3-methyl-2-pentanol, 3-methyl-3-pentanol, and $\beta$-glucuronidasesulphatase preparation from Helix pomatia (containing 100 Fishman units $\beta$-glucuronidase and 1000 Roy units arylsulphatase $/ \mathrm{ml}$, a product of IBF, Villeneuve-La-Garenne, France). A preliminary analysis by the method described above showed that the 2-methylpentane and the 3methylpentane preparations contained hexane at $3 \cdot 6 \%$ and $0 \cdot 8 \%$ (both $\mathrm{v} / \mathrm{v}$ ), respectively.

STATISTICAL ANALYSIS

Simple regression analysis ${ }^{7}$ was used when necessary.

\section{Results}

DOSE DEPENDENT ADSORPTION OF METHYLPENTANES ON CARBON CLOTH

When carbon cloth was exposed to 2- or 3methylpentane at $50,100,200$, or $400 \mathrm{ppm}$

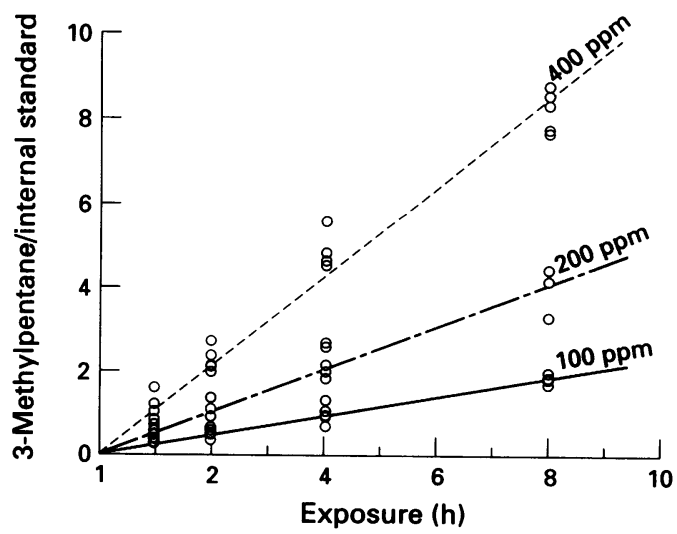

Figure 2 Increase in the amount of 3-methylpentane concentration and exposure duration. 3-

Methylpentane/internal standard on the vertical axis is in an arbitrary unit (the ratio of peak area). Each point indicates one measurement. The solid, broken, and dotted lines are calculated regression lines. adsorbed on a carbon cloth as a function of vapour 
Table 2 Concentrations of urinary metabolites after treatment with various amounts of the enzyme preparation

\begin{tabular}{lllllr}
\hline $\begin{array}{l}\text { Enzyme } \\
\text { volume } \\
(m l)^{\star}\end{array}$ & \multicolumn{4}{l}{ Metabolite concentration $(\mu g / l)$} \\
\cline { 2 - 6 } & 2-Methyl-1-pentanol & 2-Methyl-2-pentanol & 3-Methyl-2-pentanol & 3-Methyl-3-pentanol & 2-Methylpentane-2,4 diol \\
\hline $0 \cdot 0$ & $0(0 \cdot 0)$ & $1078(27 \cdot 9)$ & $0(0 \cdot 0)$ & $0(0 \cdot 0)$ & $8035(35 \cdot 7)$ \\
$0 \cdot 1$ & $81(119 \cdot 1)$ & $2187(56 \cdot 6)$ & $1331(50 \cdot 1)$ & $156(46 \cdot 6)$ & $19127(85 \cdot 0)$ \\
$0 \cdot 3$ & $74(108 \cdot 8)$ & $3287(85 \cdot 1)$ & $2190(82 \cdot 5)$ & $272(81 \cdot 2)$ & $21597(96 \cdot 0)$ \\
$0 \cdot 5$ & $68(100 \cdot 0)$ & $3862(100 \cdot 0)$ & $2656(100 \cdot 0)$ & $335(100 \cdot 0)$ & $22491(100 \cdot 0)$ \\
$0 \cdot 7$ & $67(98 \cdot 5)$ & $4227(109 \cdot 5)$ & $2900(109 \cdot 2)$ & $372(111 \cdot 0)$ & $22892(101 \cdot 8)$ \\
\hline
\end{tabular}

*Enzyme volume added to $5 \mathrm{ml}$ of the urine sample for 24 hour hydrolysis at $36^{\circ} \mathrm{C}$

Values are means of three determinations of a pooled urine sample (percentage ratio taking the amount with $0.5 \mathrm{ml}$ of the enzyme preparation in parenthesis)

Coefficients of variations were $<3 \%$, except $<5 \%$ for 2 -methyl-1-pentanol

for $1,2,4$, or 8 hours, and the amount of the solvent adsorbed was compared with the exposure dose (the exposure duration and exposure concentration), it was found that the amount absorbed was proportional to the duration as well as the concentration. Figure 2 shows the case of 3-methylpentane exposure. The results were essentially reproducible when 3-methylpentane was replaced by 2 -methylpentane. Thus, the amount of methylpentane (regardless of 2- or 3-isomer) can be expressed as $Z=$ $0.0025 \times X \times Y$, where $Z$ is the amount of methylpentane (the ratio of methylpentane peak area to that of the internal standard) and $X$ is the exposure duration (hours) and $Y$ is the exposure concentration (ppm). The parameter 0.0025 was experimentally obtained.

When the carbon cloth was exposed to one of the two methylpentane isomers for 15 minutes at various concentrations, and the amount detected by the GC analysis was compared with the amount estimated by the equation cited above, it was found that the percentage ratio of the detected amount over the estimated amount was $95 \cdot 3 \%, 88.0 \%$, and $110.4 \%$ at 100,200 , and $400 \mathrm{ppm}$, respectively, with an average of $98 \%$ for 2methylpentane, and was $98.9 \%, 84.3 \%$, and $106.4 \%$ at 100,200 , and $400 \mathrm{ppm}$, respectively, with an average of $97 \%$ for 3methylpentane. Based on the data presented, the cloth seemed to respond quantitatively to short term exposure as well as to long term steady exposure.

\section{EXTRACTION EFFICIENCIES OF EXPECTED METHYLPENTANE METABOLITES BY DICHLOROMETHANE}

About $40 \mu \mathrm{g}$ of each sample (about $8 \mu \mathrm{g} / \mathrm{ml}$ urine or $20 \mu \mathrm{g} / \mathrm{ml}$ dichloromethane) of expected metabolites of 2-methylpentane (2methyl-1-pentanol, 2-methyl-2-pentanol, 2methyl-3-pentanone, 2-methyl-3-pentanol, 2-methyl-4-pentanol, 2-methylpentane-2,4diol) and those of 3-methylpentane (3-methyl2-pentanone, 3-methyl-2-pentanol, 3-methyl3-pentanol) were tested for extraction efficiency. The extraction efficiency was assessed by dissolving in urine or dichloromethane followed by GC analysis as described in the materials and methods section. It was found that these compounds were not detectable in the urine from 15 non-exposed subjects. The analysis showed that the extraction efficiency was $77 \%$ or higher regardless of alcohols or ketones (table 1), except that the efficiency was as low as $8 \cdot 7 \%$ for 2 -methylpentane-2,4diol; the presence of two hydroxyl groups in the molecule would suggest that it is hydrophilic.

OPTIMAL AMOUNT OF ENZYME PREPARATION FOR HYDROLYSIS

An experiment was conducted to determine the optimum amount of the enzyme preparation (for details, see the materials and methods section) for enzymatic hydrolysis of urine. Thus, five portions ( $5 \mathrm{ml}$ each) of a urine sample (prepared by pooling several samples from exposed workers) were incubated at $36^{\circ} \mathrm{C}$ for 24 hours in the presence of zero to $0.7 \mathrm{ml}$ of the enzyme preparation, and dichloromethane extracts of the sample were analysed three times for metabolites. Table 2 summarises the results of the important metabolites, in terms of the means of the net amounts and the percentage ratios (taking the amounts when incubated with $0.5 \mathrm{ml}$ of the enzyme preparation as $100 \%$ ). The amounts of 2 -methyl2-pentanol, 3-methyl-2-pentanol, 3-methyl-3pentanol, and 2-methylpentane-2,4-diol almost reached a plateau when the urine sample was incubated with $0.5 \mathrm{ml}$ of the enzyme preparation. In contrast, the amount of 2methyl-1-pentanol was maximal when the urine was incubated with $0.1 \mathrm{ml}$ of the enzyme preparation, and slightly decreased with more of the preparation. Accordingly, $0.5 \mathrm{ml}$ of the enzyme preparation was selected as the optimal amount for routine enzymatic hydrolysis at $36^{\circ} \mathrm{C}$ for 24 hours.

QUALITATIVE ANALYSIS OF URINE FROM RATS EXPOSED TO 2- OR 3-METHYLPENTANE AFTER ENZYMATIC AND ACID HYDROLYSES

When the urine samples from rats exposed to 2-methylpentane at $200 \mathrm{ppm}$ were analysed by the direct method, the analysis gave peaks for 2-methyl-1-pentanol, 2-methyl-2-pentanol, 2methyl-4-pentanol, and 2-methylpentane-2,4diol (as identified by GC-MS), of which the peak for 2-methyl-2-pentanol (peak 1) seemed to be the largest (fig 3 (B-1)). It should be noted that the amount of 2-methylpentane2,4-diol should be much larger than the small peak (peak 7) suggests perhaps because the efficiency of extraction of this diol from the water phase to dichloromethane was not high (table 1). When the same urine was analysed by the enzymatic hydrolysis method (fig 3 (B2 )) or the acid hydrolysis method (fig 3 (B-3)), more peaks appeared with larger peak areas, and it was especially so with the acid hydrolysis method. After acid hydrolysis, an unidentified peak appeared between the peaks for 2methyl-3-pentanone and 2-methyl-3- 
By direct method
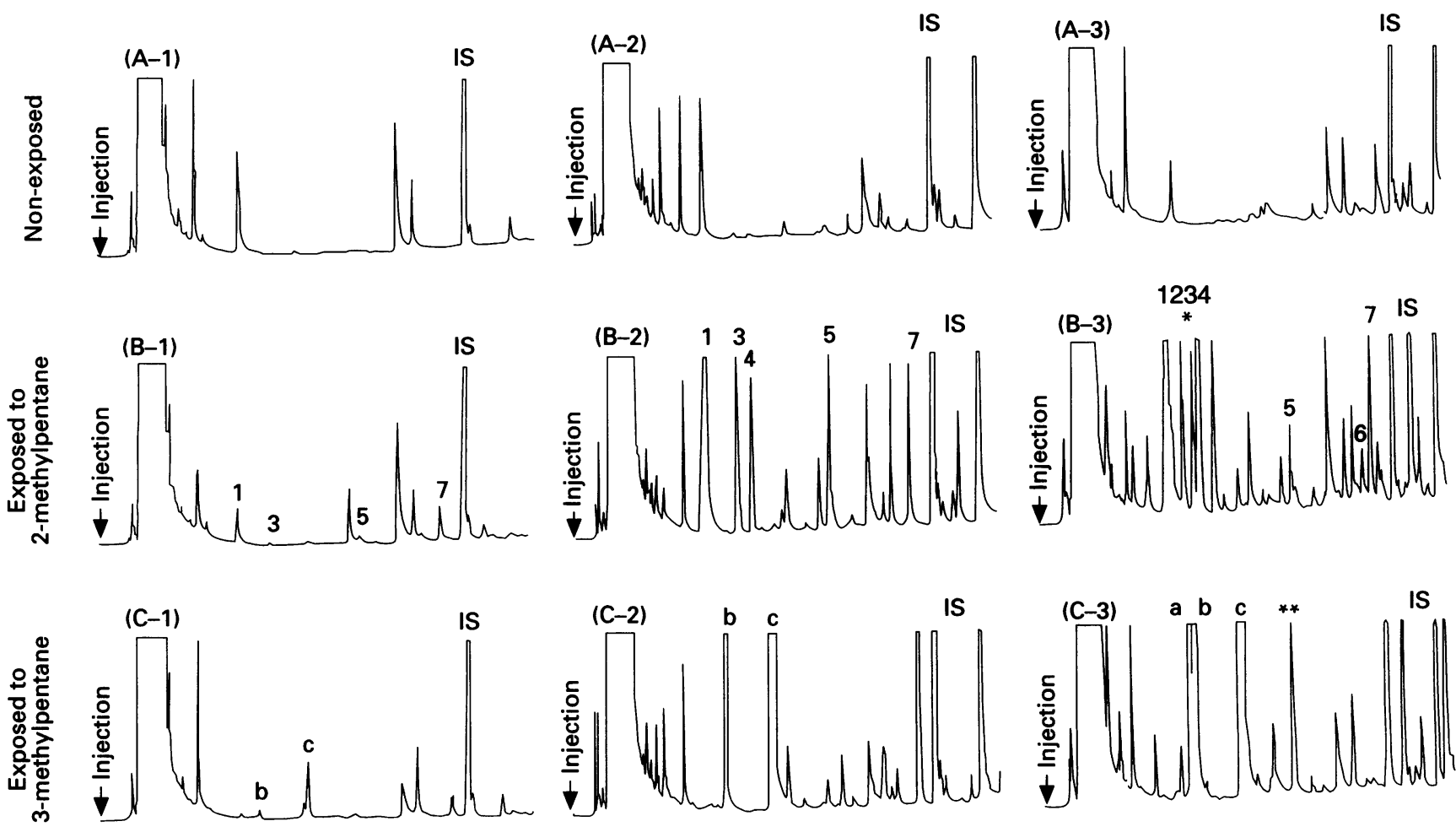

\begin{tabular}{|c|c|}
\hline 1 = 2-Methyl-3-pentanol & $7=2-$ Methylpentane-2,4-diol \\
\hline 2 = 2-Methyl-3-pentanone & a = 3-Methyl-2-pentanone \\
\hline $3=2-$ Methyl-4-pentanol & $b=3-$ Methyl-3-pentanol \\
\hline $4=2-$ Methyl-3-pentanol & $c=3-$ Methyl-2-pentanol \\
\hline $5=2-$ Methyl-1-pentanol & ${ }^{*}=2-$ Methylpentanol \\
\hline $6=2,5$-Hexanedione & ${ }^{* *}=3$-Methylene-2-pentanone \\
\hline
\end{tabular}

Figure 3 Chromatograms for urinary metabolites as analysed under three pretreatment conditions. The chromatograms are those for urine from a non-exposed rat analysed by the direct method $(A-1)$, by the enzymatic hydrolysis method $(A-2)$, and by the acid hydrolysis method $(A-3) ;$ for urine from a rat exposed to 2-methylpentane by the direct method (B-1), by the enzymatic hydrolysis method (B-2), and by the acid hydrolysis method (B-3); for urine from a rat exposed to 3-methylpentane by the direct method $(C-1)$, by the enzymatic hydrolysis method $(C-2)$, and by the acid hydrolysis method (C-3). For the direct, enzymatic hydrolysis, and acid hydrolysis method, see the materials and methods section. The peaks with asterisks show the chemicals tentatively identified by GC-MS.

pentanol (the peak with a * mark in fig 3 (B-3)). This peak was tentatively identified by GC-MS as 2-methylpentanal, but the lack of the authentic 2-methylpentanal made it difficult to carry out further identification or measurement.

A similar analysis of the urine from rats exposed to 3-methylpentane with the direct method gave small peaks for 3-methyl-2-pentanol (peak c) and 3-methyl-3-pentanol (peak b) (fig $3(\mathrm{C}-1)$ ). When the urine sample was treated by the hydrolysis enzyme preparation, the peak heights became notably larger (fig 3 (C-2)), and additional peaks (peaks marked with " $a$ " or ${ }^{\star \star}$ in fig 3 (C-3)) were found after acid hydrolysis. The $\star \star$ peak was tentatively identified by GC-MS as 3-methylene-pentanone, but no further identification or measurement was possible due to lack of the authentic chemical.

In contrast, essentially no peaks with the same retention times were detected when a urine sample from a non-exposed rat was analysed by the direct method (fig 3 (A-1)). Analysis after enzymatic or acid hydrolysis gave more peaks (fig 3 (A-2 and A-3)), but none of them disrupted metabolite measurement.

MEASUREMENT OF METABOLITES IN RAT URINE The concentrations of urinary metabolites in the urine of rats exposed to 2-methylpentane or 3-methylpentane at $200 \mathrm{ppm}$ for eight hours were calculated (table 3 ) taking the difference in extraction efficiency (table 1) into consideration. It is clear from the comparison of the results by the direct and enzymatic hydrolysis methods (table 3 ) that 2-methyl-2-pentanol and 3-methyl-2-pentanol are the main monoalcoholic metabolites of 2-methylpentane and 3-methylpentane, respectively, and that both urinary metabolites seemed to be excreted in conjugated forms. 
Table 3 Metabolite concentrations in the urine of rats exposed to either 2-methylpentane or 3-methylpentane at 200 ppm for 8 hours, as analysed under various hydrolytic conditions

\begin{tabular}{|c|c|c|c|}
\hline \multirow{2}{*}{$\frac{\text { Solvent exposed }}{\text { Metabolites (peak) } \dagger}$} & \multicolumn{3}{|c|}{ Hydrolysis method ${ }^{\star}$} \\
\hline & None & Enzymatic & Acid \\
\hline $\begin{array}{l}\text { 2-Methylpentane: } \\
\text { 2-Methyl-1-pentanol (5) } \\
\text { 2-Methyl-2-pentanol (1) } \\
\text { 2-Methyl-3-pentanol (4) } \\
\text { 2-Methyl-4-pentanol (3) } \\
\text { 2-Methyl-3-pentanone (2) } \\
\text { 2-Methylpentane-2,4-diol (7) } \\
\text { 2,5-Hexanedione (6) } \\
\text { 3-Methylpentane: }\end{array}$ & $\begin{array}{l}0.09(0.03) \\
0.15(0.04) \\
\text { ND } \\
0.13(0.01) \\
\text { ND } \\
1.59(0.72) \\
\text { ND }\end{array}$ & $\begin{array}{c}1.01(0.05) \\
19.53(0.95) \\
0.87(0.01) \\
1.42(0.08) \\
\text { ND } \\
8.90(0.17) \\
\text { ND }\end{array}$ & $\begin{array}{c}0.48(0.15) \\
45 \cdot 15(18.62) \\
1 \cdot 12(0 \cdot 37) \\
3.04(1.00) \\
1.23(0.39) \\
22.59(4.47) \\
1.03(0.21)\end{array}$ \\
\hline $\begin{array}{l}\text { 3-Methyl-2-pentanol (c) } \\
\text { 3-Methyl-3-pentanol (b) } \\
\text { 3-Methyl-2-pentanone (a) }\end{array}$ & $\begin{array}{l}0.57(0.52) \\
0.04(0.01) \\
\text { ND }\end{array}$ & $\begin{array}{l}33.62(2 \cdot 78) \\
6.75(1.23) \\
\text { ND }\end{array}$ & $\begin{array}{r}32.69(3.25) \\
11.81(1.28) \\
3.96(0.28)\end{array}$ \\
\hline
\end{tabular}

Values are mean (SD) $(\mu \mathrm{mol} / \mathrm{kg}$ in $24 \mathrm{~h})$ of three measurements each. The amounts are corrected for extraction efficiencies given in table 1 .

$\star$ None = the direct method; enzymatic = the enzymatic hydrolysis method; acid = the acid $\star$ None $=$ the direct
hydrolysis method.

The number or letter in parentheses denotes the identification of peaks in fig 3 . ND $=$ non-detectable.
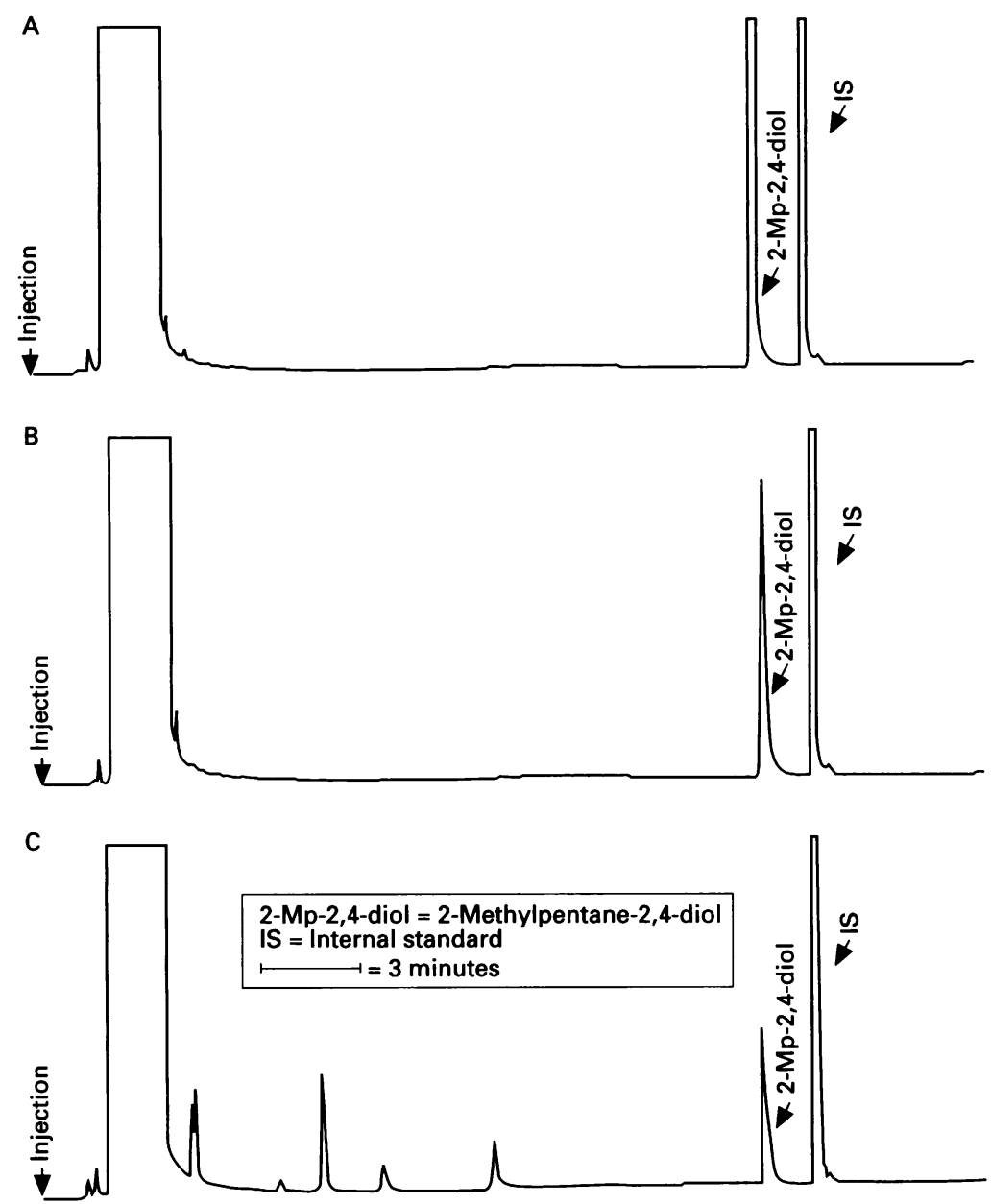

Figure 4 Formation of unidentified chemicals after acid hydrolysis of authentic 2-methyl-2,4-diol. Chromatograms are those for (A) 2-methylpentane-2,4-diol as dissolved in dichloromethane at $45.6 \mathrm{mg} / \mathrm{l}$, (B) for 2-methylpentane-2,4-diol dissolved in water at $18.24 \mathrm{mg} / \mathrm{l}$, and then extracted with dichloromethane, the peak being smaller than that in $(A)$ due to poor extraction efficiency (for the efficiency, see table 1$)$, and $(C)$ to show the appearance of peaks of unidentified chemicals when 2-methylpentane-2,4-diol (dissolved in water at $45.6 \mathrm{mg} / \mathrm{l}$ ) was treated by the acid hydrolysis method.

\section{POSSIBLE FORMATION OF METABOLITES IN} VITRO

Acid treatment resulted in increases in concentrations of several metabolites, and as such were especially remarkable in the cases of 2 methyl-2-pentanol, 2-methylpentane-2,4-diol, and 3-methyl-3-pentanol, leading to a suspicion that 2-methylpentane and 3-methylpentane might be oxidised chemically by the acid hydrolysis. Acid treatment of authentic 2methylpentane and 3-methylpentane, respectively, in the presence of urine from non-exposed rats, however, did not show formation of 2-methyl-2-pentanol, 2-methylpentane-2,4-diol, 3-methyl-3-pentanol, or any other metabolites.

It was also suspected that in vitro conversion of 2-methylpentane-2,4-diol to other metabolites was taking place. Whereas the treatment of 2-methylpentane-2,4-diol in water with the enzymatic preparation produced no peaks other than the mother peak (fig 4 (B)), the acid hydrolysis resulted in the appearance of several new peaks (fig 4 (C)). They were all small and it was not possible to identify their chemical structures by GC-MS. Their retention times were however close to those of some metabolites-for example 2-methyl-2-pentanol and to a lesser extent 3-methyl-3-pentanol. Also, 3-methyl-2pentanol when treated with acid gives an unidentified compound with the same retention time as 3-methyl-3-pentanol. Thus, it was considered that the formation of these compounds after acid hydrolysis might disturb measurements of the methylpentane metabolites.

\section{PRELIMINARY APPLICATION OF THE}

\section{ANALYTICAL METHOD TO HUMAN URINE}

\section{SAMPLES}

A preliminary analysis was carried out with urine samples from three workers (who were exposed to solvent mixtures that contained 2and 3-methylpentane and had low hexane contents) by the direct method as well as by the acid or enzymatic hydrolytic methods (table 4). The analysis by enzymatic hydrolysis showed that the main metabolites were 2methyl-2-pentanol and 3-methyl-2-pentanol, and that 2-methylpentane-2,4-diol was also detected as well as 2,5-hexanedione, which was derived from hexane. Other metabolites included 2-methyl-1-pentanol, 2-methyl-3pentanol, 2-methyl-4-pentanol, and 3-methyl3-pentanol, but they were mostly minor metabolites. When the human urine sample was treated with acid, remarkable increases in the concentration occurred in 2-methyl-2pentanol, 3-methyl-2-pentanol, 3-methyl-3pentanol, and 3-methyl-2-pentanone as was the case with rat urine. The increase in 2,5hexanedione after acid hydrolysis is in accordance with previous findings. ${ }^{714}$

\section{QUANTITATIVE RELATION IN RATS BETWEEN}

THE EXPOSURE BY INHALATION TO 2- OR

3-METHYLPENTANE AND URINARY EXCRETION OF 2- OR 3-METHYL-2-PENTANOL AND

2-METHYLPENTANE-2,4-DIOL

Because 2-methyl-2-pentanol and 3-methyl2-pentanol were the leading urinary monoalcoholic metabolites of rats exposed to 2-methylpentane and 3-methylpentane, respectively, their quantitative relation with exposure intensity was examined. The regression analysis (fig 5) showed that there was a clear linear relation between the vapour concentration for eight hour exposure and the 
Figure 5 The correlation between exposure to methylpentane vapour and urinary excretion of methylpentanol in rats. Female Wistar rats (four animals/dose) were exposed either to 2-methylpentane or 3-methylpentane for eight hours and the amounts of 2-methyl-2pentanol or 3-methyl-2pentanol in urine collected for 24 hours after the start of the exposure was analysed by the enzymatic hydrolysis method. (A) shows 2-methyl-2-pentanol excretion after 2 methylpentane exposure, and $(B)$ shows 3-methyl2-pentanol excretion after 3-methylpentane exposure. The equation of the regression line in figure 5 (A) is: $Y=-0.297+0.098 X$ $(r=0.993, P<0.01)$ and that in figure $5(B)$ is: $Y=0.353+0.144 X$ $(r=0.994, P<0.01)$

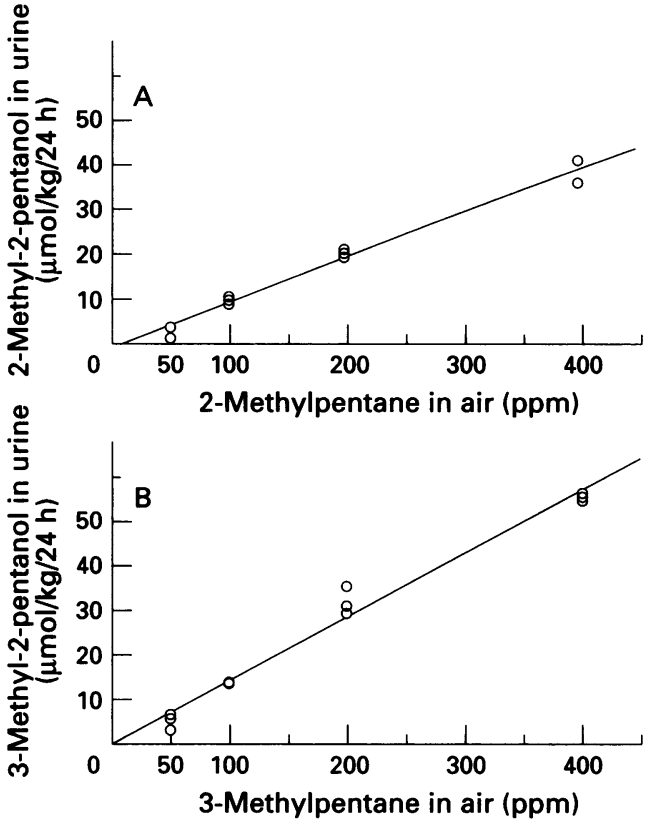

amount of monoalcohol in urine 24 hours after initiation of exposure both in the case of 2methylpentane (fig 5 (A)) and 3-methylpentane (fig 5 (B)). The regression lines passed very close to the origin and the correlation coefficient was almost one. The slope for 2-methylpentane seemed to be somewhat less steep than that for the 3-methylpentane.

It was clear that 2-methylpentane-2,4-diol was abundant in the urine from rats exposed to 2-methylpentane (table 3). Accordingly, the quantitative comparison of 2-methylpentane with 2-methylpentane-2,4-diol after enzymatic hydrolysis was carried out. The calculation gave an equation for the regression line of $Y=$ $1.811+0.040 X$ (where $X$ was 2-methylpentane in ppm (exposure for eight hours) and $Y$ was 2 -methylpentane-2,4-diol in $\mu \mathrm{mol} / \mathrm{kg}$ body weight of rats excreted in urine in 24 hours). The correlation coefficient was 0.965 which is significant $(P<0.01)$.

\section{Discussion}

The present study has made it clear that exposure to the vapour of both 2-methylpentane and 3-methylpentane, two hexane isomers, can be monitored by personal diffusive sampling with activated carbon cloth, identical to sampling for hexane. Response to short exposures of 15 minutes were within the generally accepted industrial standard of $80 \%$ to $120 \%$ of predicted values based on a linear response model developed from long term steady exposures. These data showed that the monitoring method with the carbon cloth was a satisfactory diffusive dosimeter. Additional testing under varied environmental conditions is needed to further validate its performance and use in a work setting. Clear separation from hexane on a GC column was considered essential because it will be necessary to determine the two methylpentane isomers in the presence of hexane. ${ }^{245}$ This was achieved by the use of a capillary column at a relatively low temperature of $40^{\circ} \mathrm{C}$ (fig 1 ).
Vapour exposure experiments with rats showed that 2-methyl-2-pentanol and 3methyl-2-pentanol are the main metabolites in the urine of rats exposed to 2-methylpentane and 3-methylpentane, respectively (table 3 ), and that the amounts of these metabolites are proportional to the intensity of exposure to the corresponding methylpentane isomers (fig 5). These two metabolites were detected also in the urine of workers exposed to commercial hexane, which contained 2-methylpentane and 3-methylpentane, suggesting that urinary analysis of 2-methyl-2-pentanol and 3-methyl2-pentanol can be applied to biological monitoring of exposure to 2-methylpentane and 3-methylpentane, respectively. This conclusion is in close agreement with the findings of Perbellini et al who found dose-dependent increases in methylpentanol isomers in urine of workers exposed to up to $240 \mathrm{mg} / \mathrm{m}^{3}$ (about $67 \mathrm{ppm}$ ) 2-methylpentane and $200 \mathrm{mg} / \mathrm{m}^{3}$ (about 56 ppm) 3-methylpentane. ${ }^{9}$

Because these hydroxylated compounds are present in urine in conjugated forms, hydrolysis is required before analysis. The use of a DB-1 mega-bore column made it possible to separate various oxidised metabolites simultaneously (fig 3). The application of a moderate method of enzymatic hydrolysis showed that the treatment can liberate substantial amounts of alcoholic metabolites especially 2-methyl2-pentanol and 3-methyl-2-pentanol. Also, 2methyl-1-pentanol, 2-methyl-3-pentanol, and 2-methyl-4-pentanol were detected as minor metabolites in urine of rats exposed to 2methylpentane, and 3-methyl-1-pentanol from rats exposed to 3-methylpentane. When a more drastic hydrolysis by acid was applied, the treatment resulted in a remarkable increase in 2-methyl-2-pentanol as well as 3methyl-3-pentanol. 3-Methyl-3-pentanol was not detectable after enzymatic hydrolysis. Although the acid treatment of methylpentane did not show formation of any alcohols, it has not yet been ruled out that the increases in alcoholic compounds after acid hydrolysis was due to in vitro formation rather than hydrolysis of the conjugates, because the amount of enzymatic preparation, $0.5 \mathrm{ml} / 5 \mathrm{ml}$ urine sample, is apparently sufficient (table 2 ).

At present, it is not known why larger amounts of alcohols are produced after acid hydrolysis than after enzymatic hydrolysis. Table 2 shows findings that suggest that the chances are remote that enzymatically hydrolysed metabolites (with the one possible exception of 2-methyl-1-pentanol) might undergo further degradation to other compounds. Nevertheless, the in vitro formation of unidentified compounds from 2-methyl-2,4-diol after acid hydrolysis suggests that the use of enzymatic hydrolysis rather than acid hydrolysis should be recommended for the pretreatment. Perbellini et al used both enzymatic and acid hydrolysis in sequence when they analysed urine from workers exposed to commercial hexane under such analytical conditions. ${ }^{9}$ The slopes of the regression lines between methylpentane vapour exposure and corresponding methylpentanol in urine might have 
Table 4 Metabolite concentrations in the urine samples from three workers exposed to commercial hexane, as analysed under various hydrolytic conditions

\begin{tabular}{|c|c|c|c|c|c|c|c|c|c|}
\hline \multirow[b]{2}{*}{ Metabolites } & \multicolumn{9}{|c|}{ Hydrolysis method ${ }^{\star}$} \\
\hline & \multicolumn{3}{|c|}{ None } & \multicolumn{3}{|c|}{ Enzymatic } & \multicolumn{3}{|l|}{ Acid } \\
\hline $\begin{array}{l}\text { 2-Methyl-1-pentanol } \\
\text { 2-Methyl-2-pentanol } \\
\text { 2-Methyl-3-pentanol } \\
\text { 2-Methyl-4-pentanol } \\
\text { 2-Methyl-3-pentanone } \\
\text { 2-Methylpentane-2,4-diol } \\
\text { 3-Methyl-2-pentanol } \\
\text { 3-Methyl-3-pentanol } \\
\text { 3-Methyl-2-pentanone } \\
\text { 2,5-Hexanedione }\end{array}$ & $\begin{array}{l}\text { ND } \\
1 \cdot 6 \\
\text { ND } \\
\text { ND } \\
\text { ND } \\
2 \cdot 5 \\
0 \cdot 1 \\
0 \cdot 1 \\
0 \cdot 1 \\
\text { Tr }\end{array}$ & $\begin{array}{l}N D \\
0 \cdot 4 \\
N D \\
N D \\
N D \\
1 \cdot 8 \\
T r \\
T r \\
T r \\
T r\end{array}$ & $\begin{array}{l}\text { ND } \\
0 \cdot 3 \\
\text { ND } \\
\text { ND } \\
\text { ND } \\
2 \cdot 1 \\
0 \cdot 1 \\
\text { Tr } \\
\text { Tr } \\
\text { Tr }\end{array}$ & $\begin{array}{c}0 \cdot 2 \\
7 \cdot 8 \\
0 \cdot 1 \\
0 \cdot 1 \\
\text { ND } \\
3 \cdot 2 \\
15 \cdot 9 \\
6 \cdot 7 \\
\text { ND } \\
\text { ND }\end{array}$ & $\begin{array}{l}0 \cdot 1 \\
2 \cdot 8 \\
\text { Tr } \\
\text { Tr } \\
\text { ND } \\
2 \cdot 4 \\
3 \cdot 4 \\
1 \cdot 0 \\
\text { ND } \\
\text { ND }\end{array}$ & $\begin{array}{l}0 \cdot 1 \\
1 \cdot 3 \\
\text { Tr } \\
\text { Tr } \\
\text { ND } \\
2 \cdot 3 \\
1 \cdot 7 \\
0 \cdot 5 \\
\text { ND } \\
\text { ND }\end{array}$ & $\begin{array}{l}0 \cdot 5 \\
56 \cdot 6 \\
0 \cdot 5 \\
\text { ND } \\
\text { ND } \\
2 \cdot 2 \\
103 \cdot 2 \\
44 \cdot 0 \\
46 \cdot 5 \\
5 \cdot 6\end{array}$ & $\begin{array}{r}0 \cdot 2 \\
17 \cdot 7 \\
0 \cdot 2 \\
0 \cdot 3 \\
\mathrm{ND} \\
0 \cdot 9 \\
40 \cdot 0 \\
17 \cdot 0 \\
20 \cdot 9 \\
4 \cdot 3\end{array}$ & $\begin{array}{r}0 \cdot 2 \\
7 \cdot 4 \\
0 \cdot 1 \\
0 \cdot 2 \\
\text { ND } \\
0 \cdot 1 \\
9 \cdot 0 \\
2 \cdot 5 \\
24 \cdot 8 \\
6 \cdot 0\end{array}$ \\
\hline
\end{tabular}

Values (mg/l, with no correction for urine density) for three workers (workers I, II, and III) exposed to 2-methylpentane $(298,203$, and $110 \mathrm{ppm}$, respectively) and hexane $(36,27$, and 14 ppm, respectively) are given in order. It was quite probable that they were exposed also to 3methylpentane at the concentrations comparable with that of 2-methylpentane, but this could not be confirmed due to technical limitation of the time of study.

$\operatorname{Tr}=$ trace, which means that a peak was detected but was too small for measurement of the metabolite.

Other abbreviations as for table 3.
.

been affected by the increment due to acid pretreatment, especially in the case of 2methyl-2-pentanol, although not of 3-methyl2-pentanol (table 3).

2-Methylpentane-2,4-diol is a 2-methylpentane metabolite that has not been reported previously. This dihydroxylated metabolite is more hydrophilic than monohydroxylated metabolites with a lower extraction efficiency (table 1) when extracted into dichloromethane. Thus, although the peak in the chromatogram is rather small, its in vivo formation is almost comparable with 2-methyl-2-pentanol. It is not desirable to use two extraction procedures in the pretreatment, dichloromethane extraction for 2,5-hexanedione (a hexane exposure indicator ${ }^{7}$ ) and another extraction procedure for 2-methylpentane-2,4diol. Its abundant formation both in humans (table 4) and rats (table 3), a linear increase related to exposure in rats, and presence in the urine without hydrolysis (table 4) suggest that 2-methyl-pentane-2,4-diol may be another promising marker of exposure to 2-methylpentane.

This work was supported in part by a research grant (No 05304030: Head investigator, M Ikeda) in 1993-94 from the Ministry of Education, Science, and Culture of the Government of Japan to TK, HI, and MI.

1 Ono $\mathrm{Y}$, Takeuchi $\mathrm{Y}$, Hisanaga $\mathrm{N}$. A comparative study on the neurotoxicity of $\mathrm{n}$-hexane and its isomers on the peripheral nerve. Int Arch Occup Environ Health 1981;48:289-94.

2 Perbellini L, Brugnone F, Gaffuri E. Neurotoxic metabolites of "commercial hexane" in the urine of factory worklites of "commercial hexane" in the

3 Matsubara K, Akane A, Takahashi S, Shiono H, Fukui Y, Kagawa M, Maseda C. Gas chromatographic determination for forensic purpose of petroleum fuel inhaled just before fatal burning. $¥$ Chromatogr 1988;424:49-59.

4 Perbellini L, Soave C, Cerpelloni M. Solvent exposure in shoe factories. Med del Lavoro 1992;83:115-9. (In Italian with English abstract.)

5 Mutti A, Bergamaschi E, Ghittori S, Imbriani M, Franchini I. On a need of a sampling strategy in biological monitoring: The example of hexane exposure. Int Arch Occup Environ Health 1993;65:S171-6.

6 Williams RT. Detoxication mechanisms. London: Chapman and Hall, 1959:23-45.

7 Kawai T, Yasugi T, Mizunuma K, Horiguchi S, Uchida Y, Iwami $\mathrm{O}$, et al. Dose-dependent increase in 2,5-hexanedione in the urine of workers exposed to $n$-hexane. In Arch Occup Environ Health 1991;63:285-91.

8 Saito I, Shibata E, Huang J, Hisanaga N, Ono Y, Takeuchi $Y$. Determination of urinary 2,5-hexanedione concentration by an improved analytical method as an index of exposure to $\mathrm{n}$-hexane. $\mathrm{Br} \mathcal{F}$ Ind Med 1991;48:568-74.

9 Perbellini L, Brugnone F, Faggionato G. Urinary excretion of the metabolites of $\mathrm{n}$-hexane and its isomers during occupational exposure. Br F Ind Med 1981;38:20-6.

10 Koizumi A, Ikeda M. A servomechanism for vapor concentration control in experimental exposure chambers. $\mathrm{Am}$ tration control in experimental

11 Hirayama $T$, Ikeda $M$. Applicability of carbon felt to the dosimetry of solvent vapor mixture. Am Ind Hyg Assoc 7 1979;40:1091-6.

12 Ikeda M, Kumai M, Aksoy M. Application of carbon felt dosimetry to field studies distant from analytical laboratory. Ind Health 1984;22:53-8.

13 Kasahara $M$, Ikeda $M$. Spontaneous desorption of organic solvents from carbon cloth. Ind Health 1987;25:73-81.

14 Kawai T, Yasugi T, Mizunuma K, Horiguchi S, Uchida Y, Iwami $\mathrm{O}$, et al. 2-Acetylfuran, a confounder in urinalysis for 2,5-hexanedione as an $n$-hexane exposure indicator. Int Arch Occup Environ Health 1991;63:213-9. 